\title{
ISO 9001 CERTIFICATION OF THE INTERNATIONAL VACCINATIONS CENTER OF THE NATIONAL INSTITUTE OF PUBLIC HYGIENE, COTE D'IVOIRE
}

Attoh Toure, $\mathrm{H}^{*}$, Oussou R, Adam Ayéva $\mathrm{E}$, Telly A, Sangaré A, Bénié BVJ.

National Institute of Public Hygiene

Introduction

National Institute of Public Hygiene is a reference center for immunization in Côte d'Ivoire. Within this structure, the International Vaccinations Center (IVC) aims to protect people against vaccine-preventable diseases such as yellow fever and typhoid fever. In many developing countries, the risk of post-immunization manifestations and / or vaccine inefficiency remains high. Since October 2017, the IVC is one of the only immunization services certified ISO 9001 version 2015 in West Africa. The objective of this work was to describe the control- quality approach implemented around the "Achieve individual immunization" process.

\section{Method}

National Institute of Public Hygiene is located in Abidjan, economic capital of Côte d'Ivoire. It's a reference center of immunization in Côte d'Ivoire with four immunization services in 29 regions through the country :

-International Center of Immunization (ISO 9001 V 2015 certification)

-EPI Unit+++

-Anti-Rabic Center

-Collectivity Immunization Unit
For the IVC one of the challenges of the certification was the drafting of operational procedures and work instructions covering the various tasks to be carried out from the reception to the validation through the issue of the invoices, the payment and the administration of quality vaccines. To realize this work, we analyzed all these procedures, instructions and internal report.

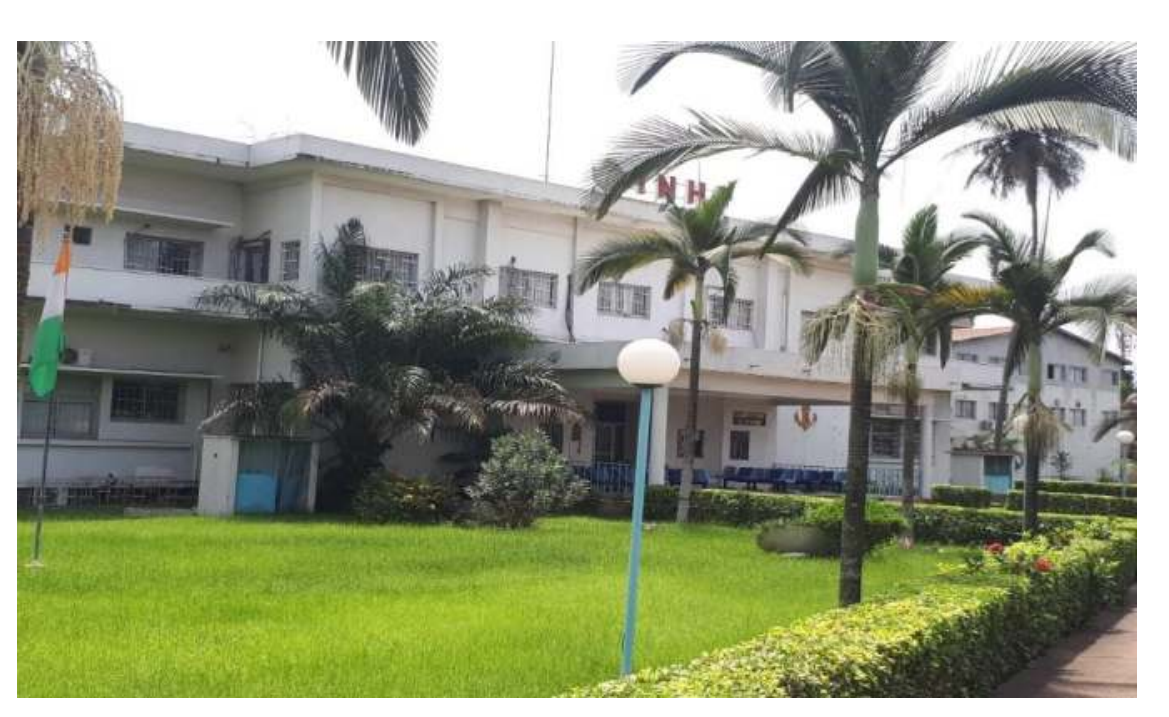

\section{Results}

The first procedure called "pre-registration procedure of the client" consists of an interview with the client to collect his needs, analyze his card or vaccination book, identify the vaccines to be administered and look for any contraindications.

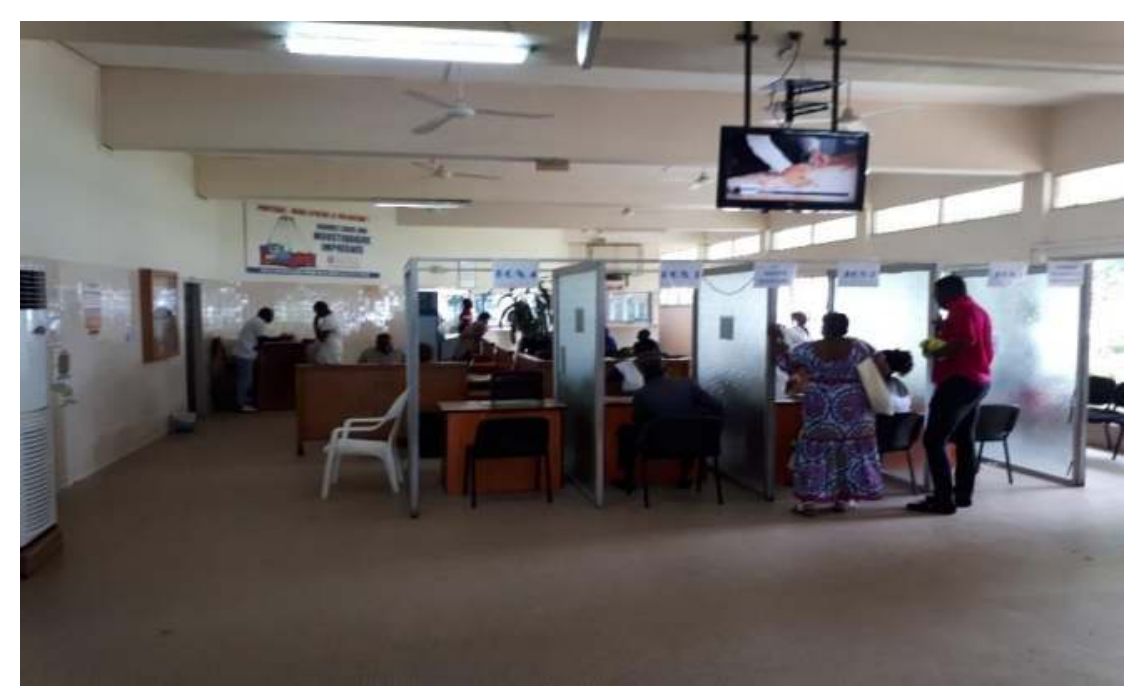

Other procedures for vaccine storage and good injection practices help ensure safe and effective immunization. The control-quality approach favored a better organization of the center, a more fluid and clear circuit for all the customers. Notable improvements include the control of process-related risks (risk of impaired vaccine quality, postimmunization events and blood exposure). No vaccine vials have been altered and no post-immunization events have been reported since certification.

\section{Conclusion}

Control-quality of services is essential in immunization services not only to ensure safe and effective immunization but also to reduce drop-out rates.

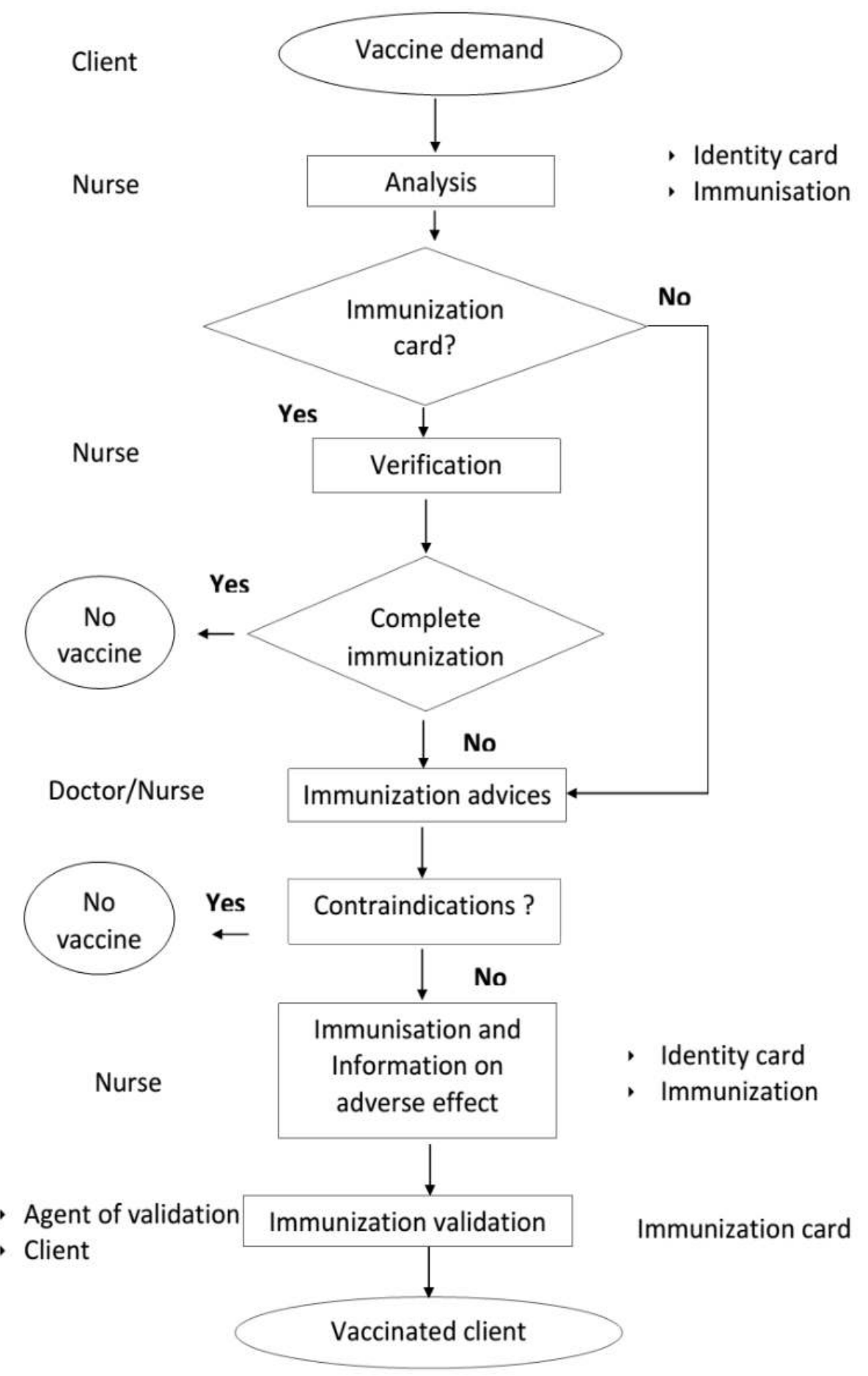

Figure 2 : process card

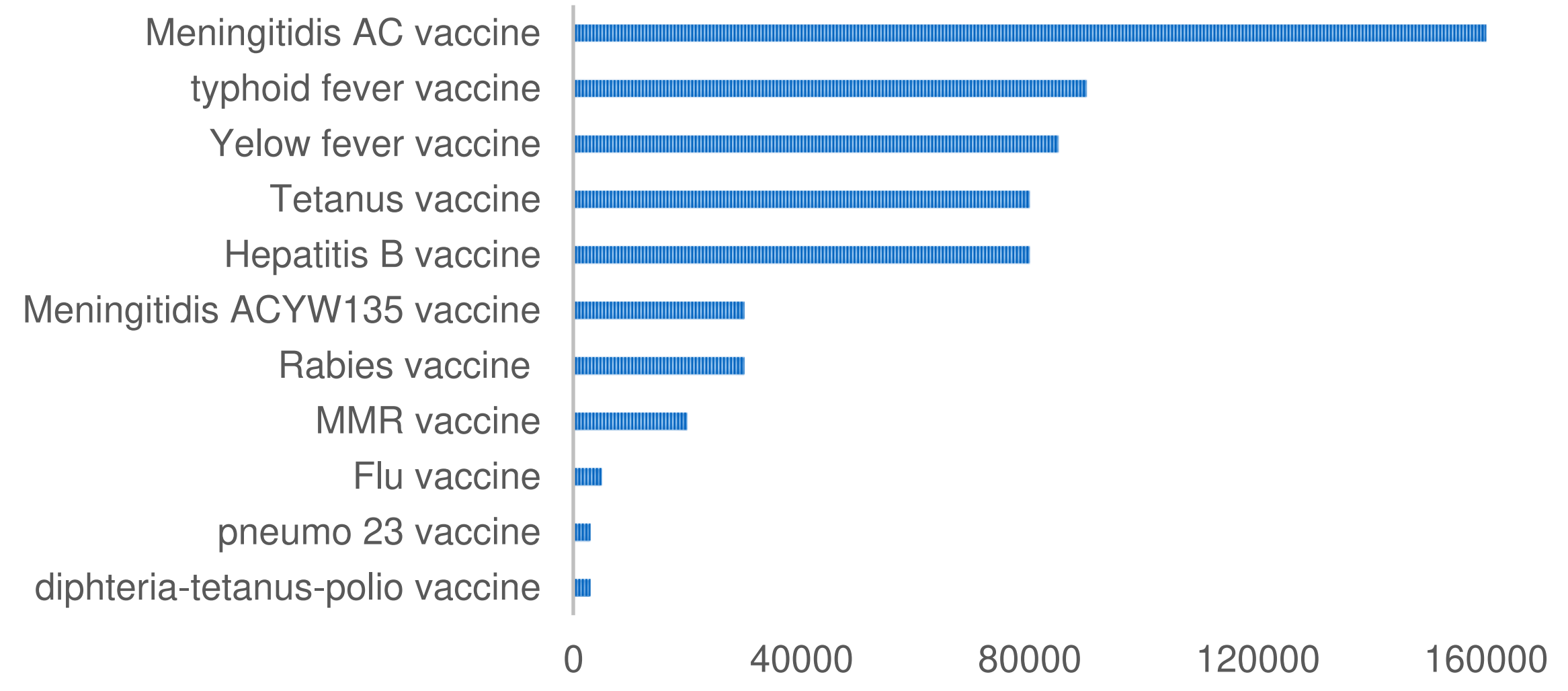

Figure 1 : number of of vaccine dose administered in 2016 in IVC 